\title{
Gone fishing? Intergenerational cultural shifts can undermine common property co-managed fisheries
}

J. Tam ${ }^{a, *}$, K.M.A. Chan ${ }^{a}$, T. Satterfield ${ }^{a}$, G.G. Singh ${ }^{a, b}$, S. Gelcich ${ }^{c}$

a Institute for Resources, Environment, and Sustainability, The University of British Columbia, Vancouver, BC, Canada

${ }^{b}$ Nippon Foundation NEREUS Program, Institute for the Oceans and Fisheries, The University of British Columbia, 2202 Main Mall, Vancouver, BC, Canada V6T1Z4

${ }^{c}$ Center of Applied Ecology and Sustainability and Centro de Conservacion Marina, Facultad de Ciencias Biologicas, Pontificia Universidad Católica de Chile, Santiago, Chile

* Corresponding author.

Email addresses: jordan.tam@ires.ubc.ca (J.Tam); kaichan@ires.ubc.ca (K.M.A. Chan); terre.satterfield@ires.ubc.ca (T. Satterfield); g.singh@oceans.ubc.ca (G.G.Singh); sgelcich@bio.puc.cl (S. Gelcich)

This is the accepted manuscript of a paper published in Marine Policy. The final version may be accessed at https://doi.org/10.1016/j.marpol.2018.01.025.

This paper is available under a CC-BY-NC-ND license.

\section{Abstract}

Conventional common property thinking assumes that a central goal of management is to maintain social-ecological systems in a healthy and resilient state, including maintaining the ability of communities to harvest across time and generations. Little research has been done, however, on how common property systems are affected by demographic shifts, the social status of emerging livelihoods, and the employment aspirations of users for their offspring. An empirical case study from Chile (well known for its common property fisheries) suggests that major socio-cultural shifts are now occurring, with a lack of entry by new fishers and an aging population of existing ones. These types of social and cultural changes are increasingly common through globalization and worldwide economic development, and pose significant policy challenges across broad classes of common property systems. The Chilean case reveals that community adaptive capacity can come at the expense of social-ecological common property systems, and highlights the need to consider the broader context of 'slow' social variables.

\section{Introduction}

Many issues of resource sustainability pertain to environmental goods susceptible to overexploitation, where extraction is difficult to regulate. Common property regimes - where ownership is shared and enforced - have been frequently suggested as a solution [1]. 
Implementing a common property regime, even according to "best practices" (e.g., Ostrom's design principles), however, is no guarantee of success [2]. For instance, common property systems can disrupt existing functioning institutions [3] or create imbalances in power and the allocation of benefits [4]. Consequently, efforts to systematically understand the contexts and factors associated with successful social and ecological outcomes continue: for example, through 'diagnostic' frame- works that explicitly incorporate feedbacks, multiple scales, and ecosystem components [5,6].

Regardless, the viability of common property systems in part hinges on collective action, including the shared desire to maintain resources, and a willingness to bear costs in time, energy, and money toward the development and enforcement of norms and regulations. However, little attention has been paid to how collective desires to maintain resources may be eroded.

Implementation and maintenance of common property systems depend on the right mix of incentives and local user interests in organizing for and investing in the system. Yet the crucial role of intergenerational change (as a 'slow' social variable) in determining the resilience of common property regimes is often missed, despite calls in social-ecological systems theory for their consideration [7]. Instead, the preponderance of attention is on 'fast' (e.g., stock recruitment) ecological variables and their direct effects on the sustainability of natural resources.

In commons problems, examples of 'slow' variables are intergenerational shifts in education levels, employment opportunities and expectations, changing notions of 'success', altered motivations, and rural-to-urban migrations. Critically, the aforementioned demographic and cultural changes could lead to a lack of recruitment of new fishers. While research on common property has considered the livelihood diversification of fishers [8,9], and the recruitment of marine species $[8,10]$, relatively little attention has been paid to recruitment of new marine users.

Through an exploration of a well-known example of a common property system, we aim to show that a creeping crisis for co-managed common property systems exists in demographic shifts, changes in the social status of livelihoods, and the employment aspirations of users for their offspring. These types of social and cultural changes are common in economic development [9] and can pose policy challenges across broad classes of common property systems.

Below, we highlight the Chilean artisanal fisheries context and similar instances of social change in fishing industries around the world. We then detail the methods and results of our investigation of slow social changes in the Chilean case study, asking how enduring the quality and nature of the system might be, or fail to be. We then discuss the relevance of our findings for common property in Chile, and potential solutions. 


\section{Social change and fishers: Aging, recruitment, and alternative livelihoods}

One of the world's best-known and highly regarded common property regimes for fisheries resources is the Territorial User Rights Fishery (TURF) system in Chile. It is a national comanagement governance regime for benthic resources.

As detailed in Gelcich et al. [11], Chile's TURF system emerged in a void, where open-access extraction of marine resources (in particular the economically valuable mollusc Concholepas concholepas, or 'loco') and roving harvesters prevailed. Due to the confluence of political crisis, plummeting resource stocks, and innovative collaborations between fishers and scientists, a new regime of governance was introduced in 1991, which has since delivered stabilized stocks.

To participate and benefit from TURFs, fishers must be members of licensed fishing associations known as syndicates (or colloquially known as caletas). Syndicates are also required to submit and pay for an initial baseline study, and be reviewed on a yearly basis. To date, over eight hundred concessions to areas of the seabed and the species within them have been assigned [12] to approximately 300 associations [13]. In addition to enabling fishers to participate in the TURF system and gaining exclusive access to resources, membership in syndicates also serves to increase social and economic security through risk-spreading and cost- and benefit-sharing. Small-scale artisanal fishers, to which the TURF system primarily applies, tend to operate boats of less than $10 \mathrm{~m}$ in length. Membership in syndicates and participation in small-scale fishing in general continues to reflect the inherited and family nature of the profession, being passed on from parents to children. Importantly, TURF participants are generally a mix of divers (who directly extract benthic resources) and fishers (e.g., who operate dive boats and engage in monitoring and enforcement). At the time of research, artisanal fishers had exclusive access to fisheries resources within five nautical miles of shore for a large section of Chile's coastline.

Since the initial implementation of the TURF system, Chile has experienced significant economic and industrial development along its coastline, which has generated demand for marine resources and opportunities for coastal communities in terms of employment (e.g., tourism and construction). These socio-cultural changes, however, may come to threaten the resilience of the system.

The effects of socio-cultural change on the persistence of small-scale fishing communities and systems have been documented worldwide, most notably in the lack of recruitment of new fishers. For example, in North Norfolk in the United Kingdom, downsizing in fishing crews, increasing start-up and operational costs, and changing professional aspirations among youth and among existing fishers for their children were identified as reasons why recruitment has become difficult [14]. As Johnsen and Vik [15] note, factors both within the fishing industry and outside of fishing can act independently or interactively to affect whether a person enters or stays in the industry. In their study, Norwegian fishers who had exited the industry cited educational and other occupational opportunities, poor working conditions, and personal lifestyle preferences (e.g., insufficient time with family) as causes. Johnsen and Vik [15] 
additionally note that these reasons may be inter- acting with changes in the broader Norwegian welfare state and reductions in the size of the fishing fleet.

Similarly, a recorded dearth of interest among youth to participate in fisheries was found in a recent study in Newfoundland, Canada [16]. In Newfoundland, youth perceptions that fishing opportunities are few and are of low-status, and that greater job prospects exist elsewhere are being compounded by the erosion of social ties and capital from outmigration, giving even fewer reasons for potential fishers to stay. The trend of aging fishers is also noted in Taiwan [17], Japan [18], and other OECD countries - including France, Scotland, Australia, and the United States [19].

What is clear from recent studies is that recruitment and exit from fishing is not a simple phenomenon with single causes and interpretations [20], nor are the effects of socio-cultural change homogenous across age classes and community members [21].

Despite this, in the realm of common pool natural resource management, the effects and implications of 'slow' socio-cultural change have not received much attention, and examples of solutions are lacking. In addition, studies on recruitment generally have not examined these kinds of changes and their implications for sustainability in the context of celebrated common property systems.

While shifts away from the fishing profession are being addressed in parts of the world - for instance, via initiatives to enhance transferrable skills in the fishing sector in France to decrease the perception that fishing is a professional "dead-end" [19] - such efforts are piecemeal and can be of limited success if they do not address underlying causes [14]. In addition, a common thread in the academic literature is that socio-economic factors that lead to the diversification of livelihoods or transitions away from primary resource extraction are generally positive for resource sustainability $[8,22]$. Such a perspective may overlook the contributions that common property regimes like TURFs can deliver toward resource and social sustainability at larger scales.

In the context of Chile's TURF regime, fishers have become environmental stewards, more species have been protected under the system, and fishers have been able to maintain their livelihoods and diversify [11]. The TURF system thus appears to be well managed from a linked social-ecological point of view. However, given the development of Chile's economy in recent decades, there is reason to anticipate that generational differences in the perceived value and viability of fishing may threaten the TURF system. In particular, this study sought to examine whether the TURF system's future was at risk from attendant social and economic changes, including in demography and the attitudes, aspirations, and behaviours of small-scale fishers and divers in response.

\section{Methodology}

Data on Chilean small-scale fishers and divers were collected through two in-person surveys between January and March 2013. One hundred people participated in the first survey and 122 
people participated in the second survey (some participated in both); data and results reported herein are only a subset of the data obtained through the surveys. Surveys were conducted in nine Chilean communities along 200 km of coast in Region V (directly west of Santiago). Participants were recruited on syndicate-operated beaches where fishers conduct a variety of activities including landing their catch, ad- ministration, small business, and seafood processing. Convenience sampling was used. Caleta memberships ranged in size from 76 members (Los Molles) to 188 (Pichicuy), and were situated in rural as well as more urban areas.

Surveys included basic demographic questions, as well as enquiries into respondents' perceptions of the future of artisanal fisheries and the desire for their offspring to carry on artisanal fishing as a livelihood. In addition, survey respondents were given the opportunity to explain and elaborate on the reasons for their perceptions. These qualitative responses were then coded thematically according to the principal categories that emerged from the data; a response could be assigned more than one code (i.e., if a response contained more than one dominant theme). Each code was counted, and the percentage of people who mentioned each reason was calculated.

Survey participants were also asked whether their fishing effort had changed in the preceding five years, specifically whether they had started, stopped, increased, or decreased their fishing activities, or whether it had stayed the same.

\section{Results}

Survey results indicate a clear lack of desire among the current generation of fishers to see their children engaged in artisanal fishing (Fig. 1, B), and a distinct aging population structure (Fig. 2).

Artisanal fisheries will not exist in the future

(A)

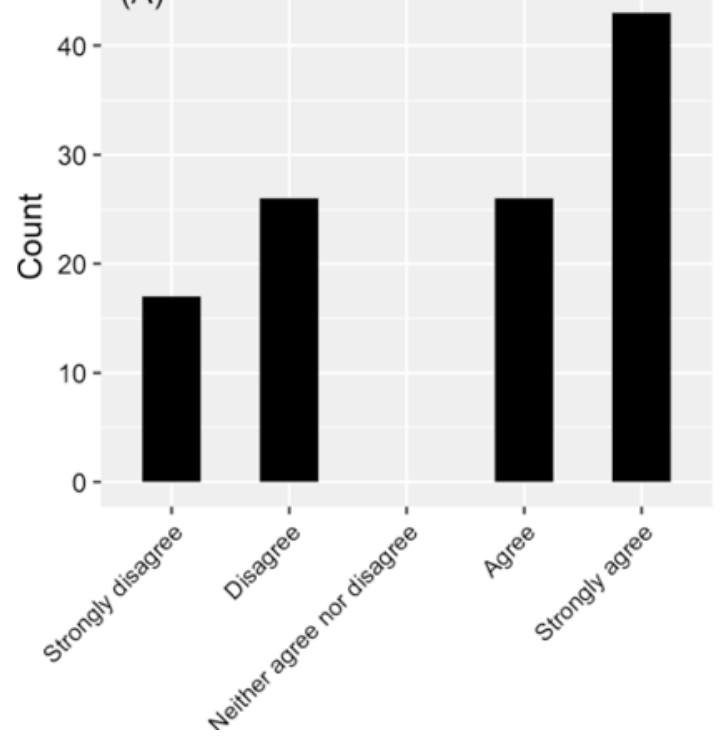

Desire children to be artisanal fishers

(B)

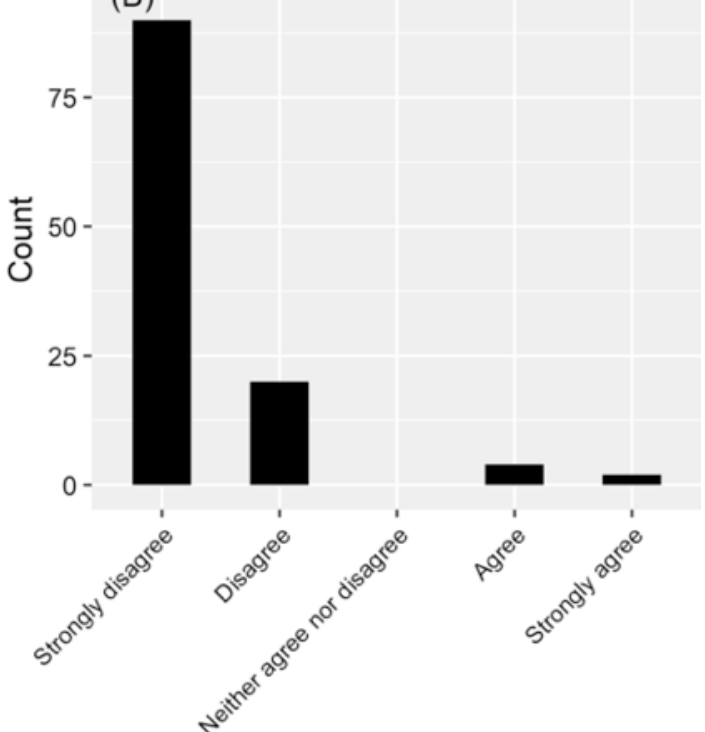

Fig. 1. The number of artisanal fishers $(N=116)$ indicating (dis)agreement about the future existence of Chile's artisanal fishing industry (A), and their desire to pass on the occupation to their children (B). 


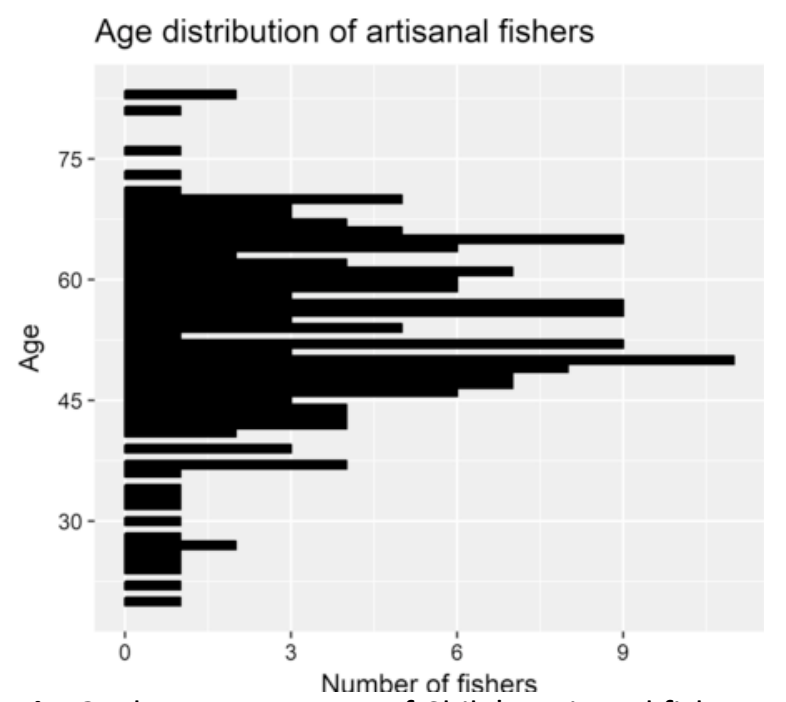

Fig. 2. The age structure of Chile's artisanal fishers surveyed $(N=184)$ over two studies in 2013. The loss of artisanal fishers could result in greater exploitation of nearshore marine resources by industrial fleets, with potentially negative implications for regional and domestic food security or sovereignty.

One survey revealed that $59 \%$ of respondents $(N=116)$ agreed or strongly agreed that artisanal fisheries had no future. Among these respondents, many identified industrial fishing and exploitation (58\%; i.e., overfishing, industrial incursion into the artisanal fishing zone, increasing technological efficiency, etc.), the declining abundance of marine resources (45\%; i.e., largely attributed to industrial overexploitation), government policies counter to artisanal fishing interests (43\%; i.e., generally reflecting perceptions that legislative changes at the time favour industrial fishing companies and vessels), a lack of entry by young fishers (14\%), and the effects of industrial development and pollution (13\%; e.g., shoreline development, resource contamination from heavy industry, etc.) as contributing factors. While $37 \%(n=43)$ of the survey sample did perceive a future for artisanal fishing, $28 \%$ of these nonetheless acknowledged a lack of youth recruitment or an overall decline in the number of fishers engaged in the profession as factors.

Notably, the vast majority of fishers (95\%) did not want their children to be involved in fishing professions. Among these participants, $40 \%$ expressed a desire for their children to seek higher education, find careers as professionals, or seek alternative opportunities and higher paying jobs with security. The difficulty and laborious conditions associated with fishing (49\%), the decline of marine resources $(28 \%)$, a relative lack of profitability $(23 \%)$, instability and lack of economic security in fishing (13\%), and the perception that fishing is dangerous and risky (13\%) were also provided by fishers as reasons for wanting their children to avoid fishing.

These perceived difficulties associated with marine harvesting suggest that current fishers may also contemplate leaving the sector. Indeed, a significant minority of surveyed fishers (42\%) had either de-creased their fishing effort in the past five years (39\%) or stopped entirely (3\%; those who stopped would generally have been missed by the survey), and relatively fewer reported increased fishing effort (29\%). 
This divestment among current fishers seems minor in comparison to changes on the horizon. That is, a decline in participation and low likelihood of artisanal fishing futures as evidenced by the absence of newcomers in the sector. Most fishers are middle-aged or older (Fig. 2); representation by younger generations is low. Out of 184 respondents (across two surveys with artisanal fishers conducted in 2013), only $11 \%$ were below the age of $40 \%$, and $20 \%$ were between 20 and 45 years old (with a median age of 54). In contrast, respondents averaged 18.38 years of age $(S D=7.93, N=182)$ when they started fishing and 28.23 years $(S D=10.32, N$ $=175$ ) when they joined their respective fishing organizations.

\section{Discussion}

\subsection{Explaining limited recruitment and retention}

The Chilean case shows that even a widely-respected common property fishery system is not immune to the effects of factors that "push" and "pull" fishers out of the system [15] to affect recruitment and retention, as has been observed in many countries around the world. Smallscale fishers in Chile are adapting and responding to socio-cultural change in ways similar to those documented elsewhere [21], such as through income diversification towards construction and tourism. Attitudes and behaviours among fishers also appear to have shifted with development in Chile, favouring education, professions of higher status and greater economic security, and reduced pressure on younger generations to fish, mirroring changes in developed country fishing contexts (e.g., 14-16).

The Chilean case is not, however, similar to patterns observed in the UK and Norway. In the latter countries, failure to recruit new entrants in small-scale fisheries have been attributed, instead, to fewer fishing opportunities due to downsizing [14], loss of access to fishing boats, increased licensing fees and fishing efficiency, greater regulatory requirements, and professionalization of fishing [15]. These themes did not emerge strongly as reasons Chilean fishers wanted their children out of fishing. Rather, reasons primarily concerned working conditions (e.g., risk of injury, physical difficulty of the work, lack of family time), the appearance of "better" options outside of fishing, and the simultaneous lack of profitability in fishing associated with declines in marine re- source abundances.

Fishers' perceptions of the future of artisanal fishing in Chile as a whole, however, did concern regulation and licensing, and were largely framed with reference to controversy and ongoing debate over a new fisheries law passed in December 2012 (rather than costs of certifications or acquiring licenses, for example). Many study participants felt the new law entrenched inequalities between artisanal fishers and the industrial fleet. Changes in the law included the allocation of 20-year renewable licenses to industrial companies rather than vessels, the ability to trade quotas, and the creation of new scientific bodies responsible for setting and allocating quotas (where previously, fishing interests were involved). In addition, many individuals cited a lack of marine re- sources resulting from overexploitation by industrial ships and a lack of new entrants as causes for a poor outlook in artisanal fishing. 
In developed country contexts, such as Norway, recruitment is a known problem around which there is vigorous debate [20]; recognition of such a threat is less prevalent in Chile's artisanal fishing sector. This may be due to the fact that Chile is not as fully developed economically, and so the problems of recruitment are only beginning to show. What is clear from the results of this and other studies, is that to understand changes in fishing and fisher behaviour, it is important to at- tend to the broader socio-cultural context in which fishing occurs, as well as the dynamics within fishing communities and families [15,20,21].

\subsection{Implications for marine management}

In Chile, the potential attrition of active TURFs due to a lack of recruitment and retention of investment by participants may mean the loss of direct and regular stewards and monitors of environmental change. This may in turn affect large expanses of sea via exposure to poaching, ingression by industrial fisheries, and pollution. In addition, fishers' engagement in small-scale fishery activities can divert human resources away from less sustainable activities such as industrial fishing and poaching. Establishing policies to maintain TURFs may therefore mitigate illegal and unregulated fishing, which is important to achieving Sustainable Development Goals related to sustainable ocean management and sustainable production and consumption [23].

The loss of a strong network of community-based common property regimes may also remove a source of sustainable seafood for locals i.e., by diverting demand to less sustainable and distant sources; [24], and a source of connection between consumers and the sea. Strong networks may also function as a valuable testing ground for adaptive management and learning, while retention of existing fishers and recruitment can help to maintain social memory and local ecological knowledge [7].

For common property regimes, solutions to these creeping crises may be elusive because 'slow' socio-cultural changes can occur in pursuit of legitimate goals (such as wanting a more stable and prosperous life for the next generation). At the same time, the impacts of these changes may have implications for resource management at larger spatial scales, such as the erosion of management and institutional networks.

While the rapid rise of educational levels and technological savvy in Chile may contribute to declining interest in fishing, it may also represent opportunities to secure common property regimes [25]. More education and diverse experiences can mean greater capacity to confront the challenges that the current generation of fishers have identified as barriers to continued fisheries. These include the ability to navigate complex bureaucratic, political, scientific, and social challenges, and to innovate in these spaces. Critically, however, these potential opportunities will likely depend on continued recruitment and engagement into fishing, as attaining formal education and technical capacity may not replace local ecological knowledge and social cooperative networks if they are lost. Moreover, as Gustavsson and Riley [21] reveal, new entrants without existing social and cultural capital may face additional barriers to entry, making continued engagement of youth from fishing families especially important. 
Since the 2013 survey, anecdotal evidence observed by the authors suggest that at least some formally educated offspring of marine users in Chile are returning to fishing due a shortage of positions in the professional job market. Thus, an opportunity may exist to reform the existing common property system into one focused on a smaller but more highly educated and trained workforce. Whether such a workforce can be harnessed to benefit natural resources management, and how this may be accomplished, is a hypothesis worth testing [25]. Regardless, it may be noted that because TURF costs are shared, smaller numbers of participant fishers may mean greater costs for those that remain, while outmigration from small communities may discourage people from returning or staying (e.g., as observed in Newfoundland; [16]); thus, staunching attrition as soon as it is recognized may be especially crucial. Ascertaining and attending to the motivations governing the (non-)participation of current and potential fishers in the profession can open a dialogue and suite of possible solutions.

Other fields, such as the extensive literature on worker motivation, have furthermore shown that variability in tasks, feelings of competence (e.g., by matching a person's skills and job tasks), ability to exert autonomy and control, opportunities to learn and for social interaction, and perceptions of contributing to a 'greater good' can all powerfully influence job engagement [6]. Findings such as these can help guide initiatives to attract newcomers and retain veterans in marine harvesting and value-added professions such as processing and related sales.

Some fishing organizations and fishers have begun taking steps to diversify and innovate their businesses beyond harvesting, including through tourism, fish mongering, restaurants, and aquaculture. While such business endeavours (relative to harvesting) may better enhance worker motivations described above, e.g., through increased task variability, these efforts tend to be dispersed and disconnected. More direct investment, coordination, and purposeful development of value-added endeavours and human resources may help foster mechanisms that generate motivations to engage in small-scale artisanal fishing.

\section{Conclusion}

Where socio-cultural changes and variables have previously been shown to be powerful forces in shaping the participation of individuals in the fishing industry (e.g., 14-16), the Chilean case highlights that similar dynamics may exist in a rapidly developing context with an established common property regime. The findings of this study also serve to warn that once established, ongoing success is not guaranteed. Com- mon property institutions will have to adapt to and accommodate slow variables whether economic, environmental, social, or otherwise. As has been highlighted previously, there are no panaceas [6], and governance regimes will be forced to shift with the context in which they are embedded, or fail to contribute to social and resource sustainability.

\section{Acknowledgements}

Data reported in this manuscript can be made available upon re- quest. The authors acknowledge support from the Financiamiento Basal (award no. FB 0002), Nucleo-milenio 
Initiative (award nos. P10-033 and NC-120086) from the Chilean Ministerio de Economia, FONDE- CYT 1160145 and the Social Sciences and Humanities Research Council of Canada.

\section{References}

[1] E. Ostrom, Governing the Commons: The Evolution of Institutions for Collective Ac- tion, Cambridge Univ Press, 1990.

[2] M. Cox, G. Arnold, S.V. Tomás, A review of design principles for community-based natural resource management, Ecol. Soc. 15 (4) (2010) 38.

[3] S. Gelcich, G. Edwards-Jones, M.J. Kaiser, J.C. Castilla, Co-management policy can reduce resilience in traditionally managed marine ecosystems, Ecosystems 9 (6) (2006) 951-966

[4] J. Aburto, G. Gallardo, W. Stotz, C. Cerda, C. Mondaca-Schachermayer, K. Vera, Territorial user rights for artisanal fisheries in Chile-intended and unintended outcomes, Ocean Coast. Manag. 71 (2013) 284-295.

[5] X. Basurto, E. Ostrom, Beyond the tragedy of the commons, Econ. delle fonti di Energia e dell'ambiente 52 (1) (2009) 35-60.

[6] E. Ostrom, M.A. Janssen, J.M. Anderies, Going beyond panaceas, Proc. Natl. Acad. Sci. 104 (39) (2007) 15176-15178.

[7] B. Walker, L.H. Gunderson, A. Kinzig, C. Folke, S. Carpenter, L. Schultz, A handful of heuristics and some propositions for understanding resilience in social-ecological systems, Ecol. Soc. 11 (1) (2006) 13.

[8] E.H. Allison, F. Ellis, The livelihoods approach and management of small-scale fisheries. Mar. Policy 25 (5) (2001) 377-388.

[9] C. Brugère, K. Holvoet, E.H. Allison, Livelihood Diversification in Coastal and In- land Fishing Communities: Misconceptions, Evidence and Implications for Fisheries Management, FAO, Rome, Italy, 2008 (Working Paper, Sustainable Fisheries Livelihoods Programme) (SFLP) (FAO/DFID).

[10] V. Almanza, A.H. Buschmann, M.C. Hernández-González, L.A. Henríquez, Can giant kelp (Macrocystis pyrifera) forests enhance invertebrate recruitment in southern Chile?, Mar. Biol. Res. 8 (9) (2012) 855-864.

[11] S. Gelcich, T.P. Hughes, P. Olsson, C. Folke, O. Defeo, M. Fernández, S. Foale, L.H. Gunderson, C. Rodríguez-Sickert, M. Scheffer, R.S. Steneck, J.C. Castilla, Navigating transformations in governance of Chilean marine coastal resources, Proc. Natl. Acad. Sci. 107 (39) (2010) 16794-16799.

[12] S. Gelcich, J.E. Cinner, J.E. Donlan, S. Tapia-Lewin, N. Godoy, J.C. Castilla, Fishers' perceptions on the Chilean coastal TURF system after two decades: problems, bene- fits and emerging needs, Bull. Mar. Sci. 93 (1) (2017) 53-67.

[13] E. González Poblete, D. Cerda, Diagnóstico del Estado y tendencias de la pesca artesanal en Chile, Dept: Subsecretaría de Pesca y Acuicultura de Chile, Valparaiso, 2013.

[14] C.S. White, Getting into fishing: recruitment and social resilience in north Norfolk's 'Cromer crab' fishery, UK, Sociol. Rural. 55 (3) (2015) 291-308.

[15] J.P. Johnsen, J. Vik, Pushed or pulled? Understanding fishery exit in a welfare society context, Marit. Stud. 12 (1) (2013) 4. 
[16] N. Power, M. Norman, K. Dupré, "The fishery went away": the impacts of long-term fishery closures on young people's experience and perception of fisheries employment in Newfoundland coastal communities, Ecol. Soc. 19 (3) (2014).

[17] W.-H. Liu, K.-L. Lin, H.-T. Jhan, T.-L. Lin, D.-L. Ding, C.-H. Ho, Application of a sustainable fisheries development indicator system (SFDIS) for better management out- comes in Taiwan offshore and coastal fishery, Coast. Manag. 39 (5) (2011) 515-535.

[18]J. Akamine, The status of the sea cucumber fisheries and trade in Japan: past and present, FAO Fish. Tech. Pap. (2005) 39-48.

[19] OECD, Structural Change in Fisheries, OECD Publishing, 2007.

[20] S.A. Sønvisen, Recruitment to the Norwegian fishing fleet: storylines, paradoxes, and pragmatism in Norwegian fisheries and recruitment policy, Marit. Stud. 12 (1) (2013) 8.

[21] M. Gustavsson, M. Riley, The Fishing Lifecourse: exploring the Importance of Social Contexts, Capitals and (More Than) Fishing Identities, Sociol. Rural. (2017).

[22] J.E. Cinner, C. Folke, T. Daw, C.C. Hicks, Responding to change: using scenarios to understand how socioeconomic factors may influence amplifying or dampening exploitation feedbacks among Tanzanian fishers, Glob. Environ. Change 21 (1) (2011) 7-12.

[23] G.G. Singh, A.M. Cisneros-Montemayor, W. Swartz, W. Cheung, J.A. Guy, T.-A. Kenny, C.J. McOwen, R. Asch, J.L. Geffert, C.C. Wabnitz, A rapid assessment of co-benefits and tradeoffs among Sustainable Development Goals, Mar. Policy (2017).

[24] G.P. Latham, C.C. Pinder, Work motivation theory and research at the dawn of the twentyfirst century, Annu. Rev. Psychol. 56 (2005) 485-516.

[25] S. Gelcich, C.J. Donlan, Incentivizing biodiversity conservation in artisanal fishing communities through territorial user rights and business model innovation, Conserv. Biol. 29 (4) (2015) 1076-1085. 